\title{
DANIEL LIBESKIND E O MUSEU JUDAICO DE BERLIM
}

Korina Costa, Andre Damaceno, Thais Espolador, Joyce Rodrigues, Yohan Turi.

Universidade do Oeste Paulista - UNOESTE, Faculdade de Engenharias e Arquitetura e Urbanismo, Presidente Prudente, SP.E-mail: korina.arq@gmail.com

\section{RESUMO}

O presente trabalho visa reportar-se sobre como o desconstrutivismo se apresenta, se evidencia, e como é concebido; suas características fundamentais para um próspero avanço da arquitetura, em âmbitos tecnológicos, sociais e culturais. A tal vertente, descaracteriza qualquer tipo de rigor que exista sobre os preceitos de edificação, principalmente a rigidez da física com suas leis absolutas, tão logo é vista como a maneira de desafiar a natureza, e junta e prontamente de causar sensações e provocar sentimentos, não sendo estáticas em seus espíritos. A partir de então, exemplifica com métodos e formas de concepções de Daniel Libeskind, com sua forma de compactuar com os direcionamentos, seu arbítrio livre, e a preocupação com o todo, partindo da história, englobando a parte cultural e de crença da liberdade que triunfa em cada povo, buscando atingir representatividade, simbologias e possibilidades, respeitando e mais que isso interagindo, sempre de forma sustentável.

Palavras chave: Daniel Libeskind, desconstrutivismo, cultura, liberdade, sentimento.

\section{DANIEL LIBESKIND AND THE JEWISH MUSEUM BERLIN}

\begin{abstract}
The present work aims to report on how deconstructivism is presented, is evidenced, and it is designed; your fundamental characteristics for a successful advancement of architecture in tecnological, social and cultural spheres. This strand, decharacterizes any kind of rigor that exists on the building precepts, mainly the physical rigidity with its absolute laws, as soon as it is seen as a way to defy nature, and jointly and promptly cause sensations and cause feelings, not being static in their spirits. Since then, exemplifies with methods and ways of Daniel Libeskind designs, with your way of condone the directions, your free will, concern for all, based on the history, encompassing the cultural part, and belief of freedom triumphing in every people, seeking to achieve representativeness, symbologies and possibilities, respecting and interacting, always in a sustainable way.
\end{abstract}

Key words: Daniel Libeskind, deconstructivism, culture, freedom, feelings. 


\section{INTRODUÇÃO}

A arquitetura desconstrutivista pauta-se em um novo caminhar, amparada por novas tecnologias, e empenhada para encontrar a essência do ambíguo, despertando os sentidos. É a arquitetura do contraste, causadora e despertadora de sentimentos e sensações, tocando o emocional do ser, sendo cada qual com afeto diferente; usa-se caminhos, direções para tal, nada programático ou definido, porém de certo é que se deve quebrar e romper com a racionalidade, rompimento esse que é a base e a essência da situação vigente para iniciar algo no desconstrutivismo (EISENMANN, 2011).

Foi Peter Eiseman quem começara o conceito de renovação na arquitetura, de compreensão, noção, e entendimento, no quesito de alternância no modo geral; a partir de então, os contemporâneos, arrojados e progressistas arquitetos, que não se encaixavam nem se acomodavam em aceitar a "mesmice" da monótona direção de edificação que raramente causara impactos de forma a aguçar e instigar as pessoas tinham um fronte para se apoiarem, um caminho aberto a seguirem.

Alguns nomes despontaram na nova jornada amparada por novas ideologias. Dentre os expoentes estão Frank Gehry, que na execução de suas obras, joga com os volumes, formas e texturas, experimentando estas formas por meio de maquetes; Zaha Hadid, arquiteta iraquiana, que em suas obras desfruta na utilização de linhas que compõem o volume da edificação, e outros nomes como o de Santiago Calatrava e Jean Nouvel que apesar de não atuarem claramente neste período, alguns autores como Rodrigo Marques atrelam seus nomes ao desconstrutivismo pelo alto uso de tecnologia associada a forma, e o despojamento pertinente de suas edificações. Compondo o período do desconstrutivismo, destaca-se também o arquiteto Daniel Libeskind, do qual o presente trabalho discorrerá a seguir.

\section{METODOLOGIA}

A presente pesquisa é do tipo quantitativa e tomou como base os levantamentos bibliográficos, buscando compreender os conceitos relativos ao tema abordado e a formulação de um estudo sobre o método projetual de Daniel Libeskind, conforme analisado na obra Museu Judaico de Berlim, nosso objeto de estudo. Os estudos foram realizados através de levantamento bibliográfico, pautados assim, nas discussões teóricas e conceituais sobre as teorias de estudo arquitetônicas e de levantamento imagético e documental, para enfim se chegar à efetuação de análises.

Segundo André e Ludke (1986) os estudos qualitativos estão diretamente relacionados à obtenção de dados descritivos, decorrentes do contato entre pesquisador e objeto de estudo, onde é muito mais significativo o processo que o produto das análises, estas que resultam da maneira própria com a qual o pesquisador a fará, devido ao seu direto envolvimento na pesquisa.

\section{DISCUSSÃO SOBRE O ARQUITETO DANIEL LIBESKIND}

Segundo Mariana Carrillo (2011), Daniel Libeskind nasceu em 12 de maio de 1946 na Polônia, o país em si passava por momentos conturbados de militância política, sua família judia, migrou para Israel em 1957, pois haviam passado por dificuldades e perseguições, e dois anos após mudar-se para Israel, mudam-se novamente, com destino para os EUA; lá estuda arquitetura e forma-se em 1970 pela Cooper Union for the Advancement of Science and Art, de Nova lorque, e em seguida em 1972 obtém o título de mestre em História e Teoria da Arquitetura da School of Comparative Studies, na Inglaterra.

Inicia sua carreira através da área acadêmica, lecionando em várias instituições conceituadas de ensino; distribuída em diversos países, sua atuação prática, na área de projetos, começa na década de 1980, quando ele começa a participar de concursos arquitetônicos, prática essa que tornara comum para Daniel. Tão logo, na data, juntamente à sua iniciação profissional 
técnica, ele funda seu primeiro estúdio, vindo de então, firmou-se como líder de seu próprio império que se inicia juntamente com sua mulher e sócia Nina Libeskind, em Berlim na data de 1989, sendo um dos motivos a vitória na seleção do concurso que escolheria o arquiteto autor do museu judaico de Berlim; escritório esse que em 2003 migra-se para Nova lorque, em razão de que Daniel foi escolhido como planejador máster da ambientalização da reformulação do novo World Trade Center, projeto em andamento, ( MACHADO, 2005, p 01).

De acordo com Marise Machado (2005, p. 02), a crença do arquiteto na responsabilidade individual de ajudar, continuadamente, a reconstruir este mundo ferido e assustado, consegue influenciar a sociedade sobre o significado da transmissão da memória, como um legado de geração em geração. "Ele tem a incrível capacidade de fundir história, memória e estrutura. Cria símbolos corajosos, espaços que gritam contra o mal e endossam a liberdade mundo afora". Dentro desse contexto histórico imposto pelo arquiteto, percebe-se isso em algumas de suas principais obras que o caracterizam muito como o Museu Felix Nussbaum, Alemanha; o plano diretor do One World Trade Center, New York; Crystals at CityCenter, Las Vegas; Vanke Pavilion, Milão; e as Dancing Tower, Seoul.

De acordo com Marise Machado (2005), Daniel Libeskind viveu em sete países e fala cinco idiomas, o que o fez de caráter culto, e de índole sã, logo que é de etnia e seguidor de preceitos judaicos, e tem por natureza a busca de acima de qualquer condicionante a realização do significado, tendo em mente e como objetivo que necessariamente tem que ser inovador, expressivo, e refletor da dinâmica vida contemporânea.

Sua preocupação com a sustentabilidade vai além de simples medidas de economias e autonomias de suas obras (consumos básicos, água, energia etc.), preocupa-se muito Daniel com a cultura de um povo, acima de suas leis que são mundanas e passageiras, tenta resgatar com todas as possibilidades as marcas de etnias que se perderam ao longo da história, respeitando-as e garantido assim que sejam salvaguardadas de relevância e de respeito; entende ele que um povo vive pelo que foi, pelo que é.

Cidades são como pessoas, têm personalidade. Acho que a arquitetura pode captar alguns aspectos implícitos da "personalidade" da cidade e contribuir com ela. Um prédio muda não só a paisagem de uma rua, de um bairro, mas o modo como as pessoas ali se relacionam. A "sustentabilidade", sobre a qual tanto se fala, está na escolha dos materiais, mas está também no impacto do prédio sobre a vida da cidade (LIBESKIND, 2010, p. 01).

Segundo Mariana Carrillo (2005), Libeskind enxerga, vê e entende que arquitetura é uma arte pública, e que é responsável pelo aquilo que constrói, mantendo apreço pela comunidade. Diz ele "Pensar o projeto antes de executá-lo é muito importante. Estudar a história do terreno, o que o prédio deve dizer, tudo isso precisa ser feito", mantendo-se assim cético à gostos, modas, tendências e afins. Quando encontrada e meditada a essência de um projeto novo, ele segue uma linha tênue entre o que representará e denotará, e sua linguagem (de Daniel); expressa-se por um dialeto e modo díspar, que abrange em ângulos imponentes, espaços labirínticos, planos inclinados e geometrias que se intersectam em abstração; assim encaixando-se na vertente desconstrutivista, não por ele, pois para o próprio a liberdade é equivalente à produção.

\section{RESULTADO DO ESTUDO DO MÉTODO PROJETUAL ATRAVÉS DO MUSEU JUDAICO DE BERLIM}

Segundo Andrew Kroll (2005), o Museu Judaico de Berlim, é uma das construções mais emblemáticas que retratam o holocausto. Ainda segundo o mesmo autor, em um edifício cheio de simbolismo, Daniel conseguiu retratar o sofrimento e a angustia que envolveu o evento em que mais de seis milhões de Judeus foram perseguidos e assassinados durante a Segunda Guerra Mundial, dando ao visitante que se propõe a andar pelos corredores do Museu Judaico de Berlim uma intensa viagem cheia de emoções e sensações. 
De acordo com Andrew Kroll (2005), em 1987, o governo de Berlim organizou um concurso visando à seleção de um projeto para a expansão do museu judaico original inaugurado em 1937, em 1988 Daniel Libeskind foi declarado o vencedor do concurso, pois seu projeto foi o único que implementou uma identidade formal radical como uma ferramenta que expressava o estilo de vida judaico, antes e depois do holocausto. Em 1999 o projeto de Libeskind foi concluído, porém como não havia objetos para serem expostos ele foi aberto somente para visitação.

Conceitualmente Libeskind queria expressar sentimentos de ausência, vazio e invisibilidade, sentimentos esse que representam o desaparecimento de toda a cultura judaica. $O$ uso da arquitetura como forma de contar uma história, proporcionando aos visitantes uma experiência totalmente emocional dos fatos e efeitos ocorridos durante o holocausto, tanto na cultura judaica quanto na cidade de Berlim, foi o toque de mestre de Daniel Libeskind nessa obra mundialmente reconhecida, analisada e apreciada (KROLL, 2005).

O local onde o museu está implantado consiste em um bairro totalmente reconstruído nos anos 60, após ele ser completamente destruído pelos ataques e bombardeios que ocorreram naquela década. Antes da execução do projeto, Libeskind ao visitar o local diz que estavam todos preocupados com a área em que o edifício seria implantado e por mais que o lugar fosse considerado importante por ele, não era o essencial, pois segundo Libeskind apud, MACHADO, 2009, p. 05:

\begin{abstract}
A história dos judeus na cidade não está ao nível do solo e sim um pouco mais abaixo, enterrada não muito profundamente. Aquele não era um projeto que eu precisasse ir as bibliotecas ou tirar fotografias para saber exatamente que orientação dar a ele. A orientação já estava pronta. Poderia ser vista mundo afora, mas tinha existido primeiramente ali, na catástrofe, na completa exterminação imposta ao povo judeu. E também na topografia da cidade, em nomes, endereços e pessoas que não eram entidades abstratas ou apenas números de identificação, mas cidadãos de fato, que continuavam a viver no seu estado de ausência, e costumavam assombrar, tal qual fantasmas, o lugar.
\end{abstract}

Os planos estruturais em concreto do museu, segundo Michel Masson (2004), expressam em forma, texturas, dimensões, luz e sombras as mensagens do autor. A fachada, por sua vez, é inteiramente coberta por chapas de zinco, que mudará de cor com o decorrer do tempo com a oxidação da liga de titânio e zinco em função da exposição ao clima, ressaltando e evidenciando as "cicatrizes" em sua fachada.

Fendas, cortes, cicatrizes, e todas as aberturas, segundo Marise Machado (2009), rompem completamente com qualquer sistema de composição, seja ele moderno ou tradicional. São resultado da superposição de duas diferentes "peles". Primeiro, a funcional, para a qual o arquiteto projetou esquadrias comuns. A segunda pele diz respeito a formal, onde Libeskind desenhou linhas sobre o mapa da cidade de Berlim, cruzando endereços, reais ou imaginários, de figuras emblemáticas para o judaísmo alemão. O diagrama resultante foi transposto para os volumes do edifício criando um padrão completamente intrigante.

Existem algumas teorias sobre a concepção da forma existente no Museu Judaico de Berlim. A mais forte, segundo Silvia Gomes (2007), consiste na ideia de que a forma é resultado de uma abstração envolvendo a estrela judaica de Davi, um símbolo muito utilizado pelo judaísmo e seus adeptos representando proteção ao povo judeu. Historicamente, segundo autores do UOL (2005), ela também foi a responsável pela identificação dos judeus pelos nazistas durante o holocausto, já que os adeptos do símbolo a usavam nas vestes, o que de certa forma mostra a genialidade e sensibilidade de Daniel na busca pelo simbolismo na concepção da forma empregada no museu, já que para ele a forma tortuosa desse "zig-zag" incorpora todas as violências, rompimentos e rupturas sofridas pelos judeus na Alemanha.

O acesso ao Museu Judaico, de acordo com Michel Masson (2004) e Marise Machado (2009), acontece dentro do prédio barroco. Sua planta baixa consiste basicamente em 3 eixos que 
se entrecruzam, onde segundo Michel Masson (2004) e Marise Machado (2009), há muitas ramificações que são parcialmente enfatizadas pelas linhas de luz no teto, estes 'caminhos', como denominou Libeskind, possuem histórias separadas, apresentando as três realidades da história judaico-germânica: continuidade, exílio e morte. Este nível se diferencia dos níveis restantes por ser o local onde estão expostos os objetos daqueles que não sobreviveram ao Holocausto.

O "Eixo da Continuidade", segundo Michel Masson (2004) e Marise Machado (2009), diz respeito à continuidade da presença dos judeus em Berlim e conduz do primeiro ao terceiro pavimento, onde se alcança os andares de exposição, onde nesse espaço, através da arquitetura Libeskind tentou demonstrar o esforço, a dificuldade de qualquer pessoa permanecer no caminho até encontrar a luz do dia.

Prosseguindo pelo primeiro eixo, surge uma bifurcação com o Eixo do Exilio, cujas paredes são levemente inclinadas e o piso é irregular. A luz do dia, segundo Michel Masson (2004) e Marise Machado (2009), é visível no fim desse mesmo corredor, que, estreitando-se conduz ao Jardim externo do Museu, representando o exilio e a imigração dos judeus da Alemanha. O Jardim é um labirinto de pilares inclinados que desestabilizam e de fato tombam o corpo do visitante, composto por 49 pilares onde do topo crescem ramos de olivas simbolizando paz e esperança na tradição judaica, no entanto plantadas em pilares de concreto são também uma imagem de aniquilamento.

O Eixo do Holocausto corta os dois anteriores levando até a Torre do Holocausto que está fora do edifício principal e de acordo com segundo Michel Masson (2004) e Marise Machado (2009), só é acessível pelo eixo subterrâneo, lançando o visitante em uma espécie de cemitério cujo acesso é escondido. O barulho da rua é audível, porém, o mundo exterior está fora de alcance. É um espaço de experiência e reflexão individual, uma área de memória na qual o vazio e a nudez representam as vítimas do genocídio alemão.

Os três pavimentos superiores destinados às exposições compõem a Linha de Conexão, responsável pela forma externa do Museu que em ziguezague impossibilita a visão antecipada do espaço seguinte. A única luz vem de cima, nada existe dentro delas, a inacessibilidade transforma a Linha de Vazios em foco central, determinando a organização das exibições em sua volta, é a encarnação da figura final do judaísmo alemão: a ausência. Essa linha une todo o prédio, sendo a última do Museu, também é simbólica, prosseguindo acima de tudo o que foi destruído.

\section{CONCLUSÃO}

Mais que causar vivência, o desconstrutivismo é provocativo, carrega em si o desafiar a natureza, tem intrínseco em seu caráter simbolizar a instabilidade, da incompletude, imperfeição e equilíbrio; é neste momento em que os adeptos libertam-se de qualquer dogma ou repressão que exista, um arquiteto sequaz é totalmente despojado de autoridade, é livre no mais firme da palavra, porém importa-se com um espírito de obra, sendo a ansa de incumbir-se de representatividade. É com tudo um protesto, uma crítica ao modo que tudo é, e porque tudo é, considera-se que somos socialmente construídos, e que isso não se insere no que já fomos, em nossa história, deduzindo assim que estamos presos ou bloqueados.

Daniel Libeskind é enquadrado na vertente; ele é um ser dinâmico, de farta índole cultural (pois viveu e vivenciou vários países), de cunho respeitoso, assim como sua crença prega, e isento de qualquer tipo de doutrina. Daniel é um visionário no quesito: criação, pois ele acredita que inovar é correto e corresponde à busca arquitetônica na contemporaneidade, assim como levar em consideração as condicionantes de aproximação com o próximo, com o lugar, com a história e com a cultura do contexto.

Libeskind quando criticado (principalmente por julgarem suas obras não harmonizarem com os respectivos entornos) é mal interpretado, pois sua obra é atemporal, e não segue os limites de fronteiras, elas significam algo maior, algo de credo irredutível, onde é pensado em um 
todo, na obra, na pessoa, na possibilidade, no lugar, na história, e na cultura, ainda sim atinge o ápice do design, impressionando, tocando, criando admiração e envolvimento; essa conexão imprescindível para um melhor diálogo entre pessoas e natureza, até com seus respectivos passados e cultura, Libeskind concebe com extrema sabedoria e destreza.

\section{REFERÊNCIAS BIBLIOGRÁFICAS}

ANDRÉ, M; LUDKE, M. Pesquisa em educação: abordagens qualitativas. São Paulo: EPU, 1986.

Autores do UOL. "Nazismo: Violência e propaganda foram as armas de Adolf Hitler" Disponível em <http://educacao.uol.com.br/disciplinas/historia/nazismo-violencia-e-propaganda-foram-asarmas-de-adolf-hitler.htm> Acesso em 19/11/2015.

BARROS, Caio; GARCEZ, Adriano. Museu Judaico (Jewish Museum). Disponível em: <http://arqcontemporanea-agcbb.blogspot.com.br/2011/06/museu-judaico-jewish-museum.html>. Acesso em $12 / 11 / 2015$.

CARRILLO, Mariana. Daniel Libeskind faz história com sua arquitetura. Disponível em <http://obviousmag.org/archives/2011/01/daniel_libeskind_faz_historia_com_sua_arquitetura.ht ml>. Acesso em: 12/11/2015.

ELOY, Edison; LEITE, Maria; REBELLO, Yopanan. Com a palavra, o Edifício. Disponível em: $<$ http://academico.riogrande.ifrs.edu.br/>. Acesso em 13/11/2015.

FARIA, Renato. Entrevista com Daniel Libeskind. Disponível em <http://au.pini.com.br/arquiteturaurbanismo/202/daniel-libeskind-fala-de-seu-novo-projeto-no-brasil-das-206886-1.aspx>. Acesso em: $14 / 11 / 2015$.

GOMES, Silvia. A estrela de Davi estilhaçada: uma leitura do Museu Judaico de Berlim de Daniel Libeskind. Disponível em: <http://www.vitruvius.com.br/revistas/read/arquitextos/07.081/273>. Acesso em: 13/11/2015.

INSTITUTO MORASHÁ DE CULTURA. A genialidade de Libeskind. Disponível em <http://www.morasha.com.br/biografias/a-genialidade-de-libeskind.html\#q=daniel Libeskind>. Acesso em: 12/11/2015.

KROLL, Andrew. "AD Classics: Jewish Museum, Berlin / Daniel Libeskind" 25 Nov 2010. ArchDaily. Disponível em: http://www.archdaily.com/91273/ad-classics-jewish-museum-berlin-daniellibeskind/. Acesso em 19/11/2015.

MACHADO, Marise. Museu Judaico de Berlim, Arquiteto Daniel Libeskind. Disponível em <https://fauforma2.files.wordpress.com/2009/08/libeskind_museu-judaico-de-berlim.pdf>. Acesso em: 12/11/2015.

MASSON, Michel. O Espaço Nas Exibições de Obras de Arte. Rio de Janeiro: PUC, 2004. 118 f. Tese (Mestre em Design) - Programa de Pós-Graduação em Design, Pontifícia Universidade Católica, Rio de Janeiro, 2004.

SITE OFICIAL MUSEU JUDAICO DE BERLIM. Disponível em <http://www.jmberlin.de/main/DE/04Rund-ums-Museum/02Museumsgeschicht.php> Acesso em 19/11/2015. 